\title{
SÍNTESE E CARACTERIZAÇÃO DO SISTEMA MgO-CeO OBTIDO POR INTERMÉDIO DO MÉTODO DOS PRECURSORES POLIMÉRICOS
}

\begin{abstract}
C. S. PINTO ${ }^{1}$, E. A. V. FERRI ${ }^{1}$
${ }^{1}$ Universidade tecnológica Federal do Paraná, Curso de Bacharelado em Química E-mail para contato: cristian_sp.15@hotmail.com; eferri@utfpr.edu.br

RESUMO - O sistema $\mathrm{MgO}-\mathrm{CeO} 2$ foi sintetizado por intermédio do método dos precursores poliméricos e as propriedades desta mistura de óxidos investigadas. Resultados de análise térmica mostraram atmosfera de ar sintético ser favorável a decomposição da matéria orgânica provinda do método e formação do sistema devido a sua ação oxidativa sobre o material. Sobreposições de fichas cristalográficas JCPDS no difratograma de raios $\mathrm{X}$ do produto obtido comprovam a presença de $\mathrm{MgO}$ e $\mathrm{CeO}_{2}$. Os difratogramas em todas as temperaturas mostram a evolução da cristalinidade com o aumento da temperatura de calcinação. Análises de fotoluminescência do material mostraram elevada atividade nas calcinações em 300 e $1000^{\circ} \mathrm{C}$ devido a ordem, desordem e alta cristalinidade intrínseca do material. Microscopia Eletrônica de varredura feita nas amostras de 700 e $1000^{\circ} \mathrm{C}$ mostraram aglomeração das partículas, policristalinidade e aumento do tamanho de grão com a elevação da temperatura de calcinação.
\end{abstract}

\section{INTRODUÇÃO}

As propriedades de materiais funcionais muitas vezes são decorrentes da forma como são sintetizados. Sendo assim, é possível desenvolver métodos para se controlar certas características desejadas destes materiais para diversas aplicações [1-2].

Um dos métodos utilizados em grande escala para a produção de materiais nanométricos é o método de Pechini ou método dos precursores poliméricos [3-5].

O cério é um dos elementos utilizados para síntese de óxidos destinados a variadas aplicações decorrentes de suas propriedades. Algumas aplicações interessantes de materiais contendo óxido de cério $\left(\mathrm{CeO}_{2}\right)$ são na área da catálise [6-7], na produção de energia limpa como produção de $\mathrm{H}_{2}$ [8] e ainda como agente de efeito na síntese de outros materiais [9].

Este elemento, o cério, é da família dos lantanídeos e pertencente a uma classe de elementos denominados terras raras. Destes, o cério é um dos mais utilizados devido as suas aplicabilidades antes citadas. 
O presente estudo tem como objetivo a síntese do sistema $\mathrm{MgO}-\mathrm{CeO} 2$ por intermédio do método dos precursores poliméricos e o estudo das características do material obtido através de variadas técnicas de caracterização.

\section{MATERIAIS E MÉTODOS}

\subsection{Preparação da Resina Polimérica}

Para a preparação da resina polimérica precursora, dissolveu-se o ácido cítrico em água destilada a uma temperatura de $50^{\circ} \mathrm{C}$ sob constante agitação. Em seguida, adicionou-se o nitrato de cério a esta solução para permitir a reação de quelatação entre o ácido e os íons cério (IV). A relação estequiométrica utilizada foi de um mol de nitrato de cério para três mols de ácido cítrico a fim de garantir a completa quelatação dos cátions pelo ácido. Este sistema foi mantido a uma temperatura em torno de $60^{\circ} \mathrm{C}$ e sob agitação constante até que fosse observada uma solução transparente.

$\mathrm{Na}$ sequência, quantidades estequiométricas de acetato de magnésio foram dissolvidas na solução do citrato de cério juntamente com mais ácido cítrico a fim de se manter a relação molar. Após a completa homogeneização, adicionou-se o etilenoglicol na proporção 60/40 em massa com o ácido cítrico e a temperatura foi elevada para $75^{\circ} \mathrm{C}$ de modo a promover a reação de poliesterificação.

\subsection{Preparação dos Pós Cerâmicos, Etapas de Calcinação e Caracterização}

Para a obtenção dos pós cerâmicos, a resina polimérica foi submetida a uma précalcinação em forno convencional a $300^{\circ} \mathrm{C}$ durante duas horas, com o objetivo de promover a pirólise da mesma, processo no qual o polímero pirolisado corresponde a um produto rico em matéria orgânica, denominado "puff". Após a obtenção do "puff", este foi desaglomerado manualmente em almofariz e pistilo. Em seguida, estes pós foram calcinados em diferentes temperaturas (de 400 até $1000^{\circ} \mathrm{C}$ ) durante duas horas com taxa de aquecimento de $7^{\circ} \mathrm{C} / \mathrm{min}$ e levados para a caracterização.

As técnicas utilizadas para caracterizar os pós precursores obtidos foram: Análise Termogravimétrica (TG), Análise Térmica Diferencial (DTA), Termogravimetria Diferencial (DTG), Difratometria de Raios-X (DRX), Análise de Fotoluminescência (PL) e Microscopia Eletrônica de Varredura (MEV).

\section{RESULTADOS E DISCUSSÃO}

\subsection{Análise Térmica}

A Figura 1 ilustra o comportamento térmico do pó precursor calcinado a $300^{\circ} \mathrm{C}$ durante duas horas ("puff") que foi estudado por meio de medidas de TG-DTG-DTA. 
Figura 1 - Análise Termogravimétrica (TG) e Análise Térmica Diferencial (DTA) e Análise Termogravimétrica Diferencial (DTG) do pó precursor obtido a $300^{\circ} \mathrm{C}$, em atmosfera de ar Sintético (a) e atmosfera de Nitrogênio (b).

(a)

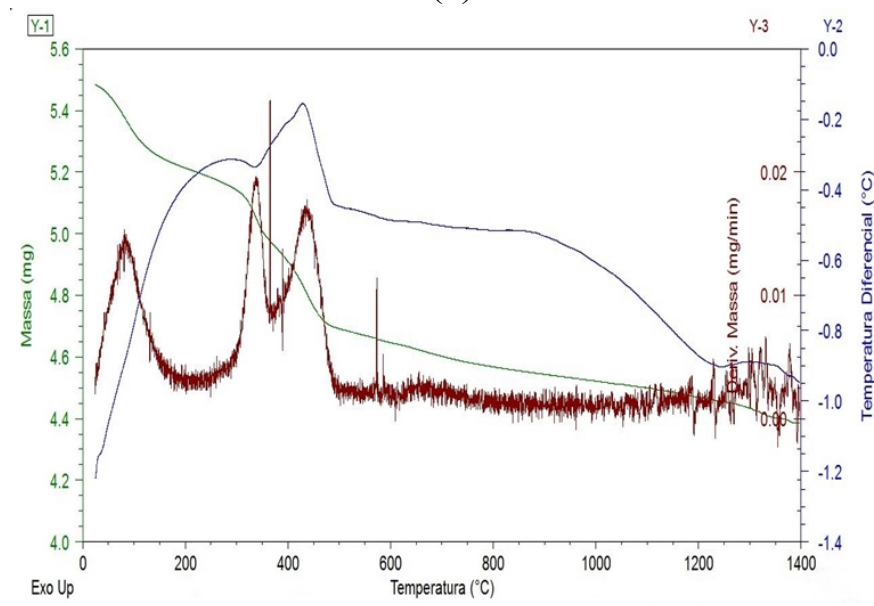

(b)

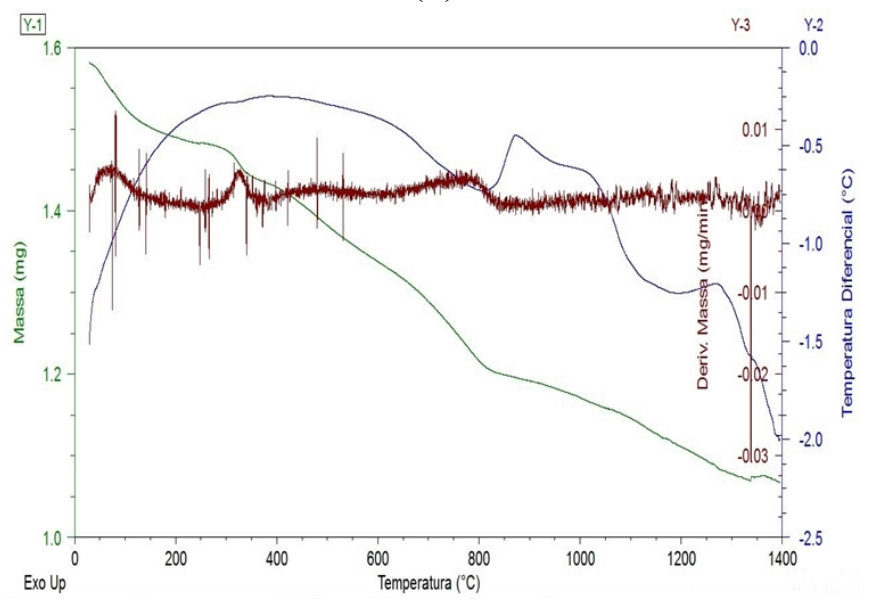

Observando-se o comportamento térmico da amostra em ar sintético na figura 2, podese verificar pela curva DTG (vermelho) três etapas de perda de massa bem evidentes. Nota-se que, para a primeira perda de massa, a curva DTA apresenta um comportamento endotérmico devido a isso e à temperatura à qual esse evento de perda de massa ocorre (aproximadamente 100). Pode-se associar essa etapa à eliminação de água decorrente de umidade presente na amostra. As duas perdas posteriores em aproximadamente 350 e $450^{\circ} \mathrm{C}$ correspondem a dois eventos consecutivos e/ou simultâneos devido à proximidade e comportamento da curva. Através da curva DTA (azul) sobre as perdas mostradas no DTG em 350 e $450^{\circ} \mathrm{C}$, observa-se que tratam-se de eventos exotérmicos, o que nos permite associar estas perdas à degradação oxidativa de matéria carbonácea e oxidação dos metais presentes pela atmosfera oxidativa.

Para o comportamento térmico do material em atmosfera de nitrogênio mostrado na figura 2, pode-se observar por intermédio das curvas TG (verde) e DTG que a perda de massa ocorreu muito mais lentamente e ao longo de toda a faixa de temperatura da análise, isto é decorrente da atmosfera não ser oxidativa e, assim, não permitir a eliminação do material carbonáceo mais rapidamente. Através da curva DTA, observam-se eventos endotérmicos associados às pequenas perdas de massa, o que caracteriza, possivelmente, volatilização deste material orgânico, processo que ocorre lentamente, como observado pela curva TG.

\subsection{Difratometria de Raios $X$}

A Figura 2 mostra o difratograma de raios $\mathrm{X}$ obtido para as amostras tratadas termicamente de 300 a $1000^{\circ} \mathrm{C}$ e o difratograma com as sobreposições das fichas cristalográficas JCPDS. Como podem ser observadas na figura, as amostras tratadas em temperaturas de 300 a $500^{\circ} \mathrm{C}$ apresentam ordem-desordem estrutural devido à transformação de fases, ou seja, nestas condições de tratamento térmico, ainda não alcançaram completa organização estrutural em longas distâncias. 
Figura 2 - (a) Difratograma de Raios-X (DRX) dos pós precursores obtidos em cada temperatura de calcinação e (b) Difratograma da amostra calcinada a $1000 \mathrm{com}$ as respectivas fichas cristalográficas dos óxidos.

(a)

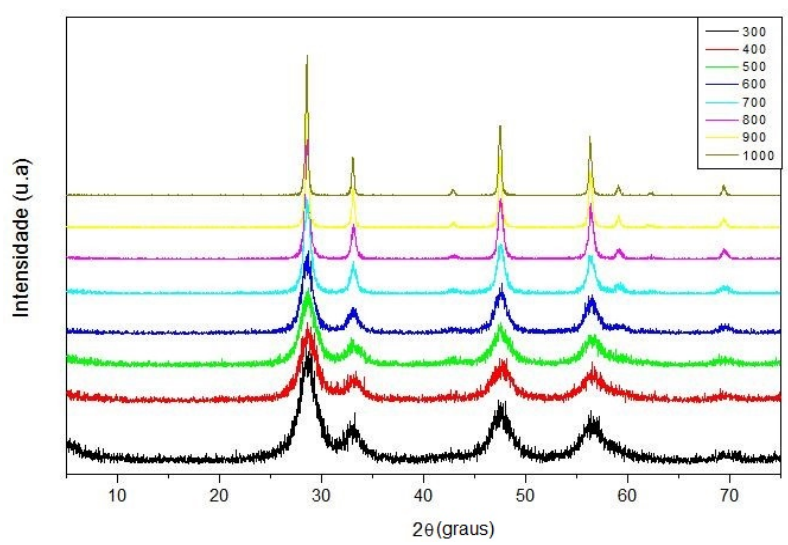

(b)

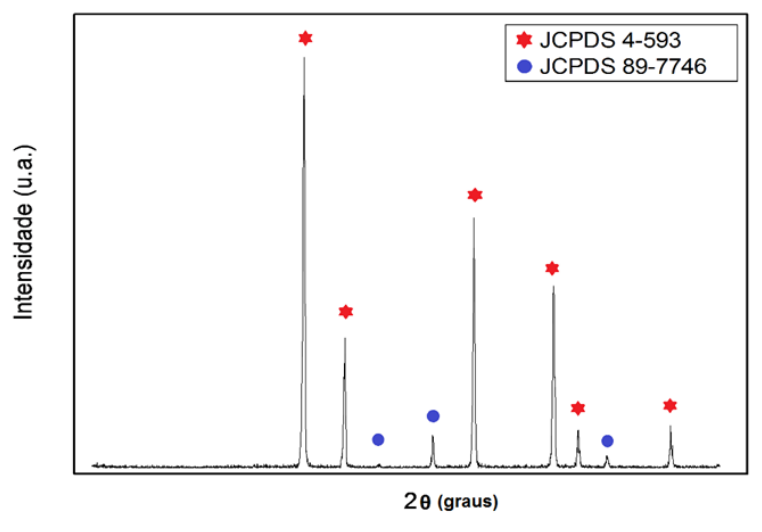

Pode-se observar que nas temperaturas de calcinação 300 a $600^{\circ} \mathrm{C}$, as amostras apresentam ordem-desordem estrutural devido à transformação de fases, ou seja, nestas condições de tratamento térmico ainda não alcançaram completa organização estrutural em longas distâncias. $\mathrm{O}$ início da cristalização das fases do sistema é na temperatura de $700^{\circ} \mathrm{C}$, em que se observa o aparecimento dos picos de difração melhores definidos, indicando que, acima desta temperatura, as amostras estão organizadas a longas distancias. As fases podem ser indexadas como uma estrutura cúbica com grupo espacial Fm-3m segundo as fichas JCPDS $n^{\circ}$ 4-593 e 89-7746. Pode-se observar que, com o aumento da temperatura de tratamento térmico, os picos de difração tornam-se mais finos, indicando o aumento no tamanho das partículas.

\subsection{Fotoluminescência}

A figura 3 mostra a atividade fotoluminescente dos pós precursores de cada temperatura de calcinação.

Figura 3 - Atividade Fotoluminescência para cada temperatura de calcinação dos pós precursores obtidos.

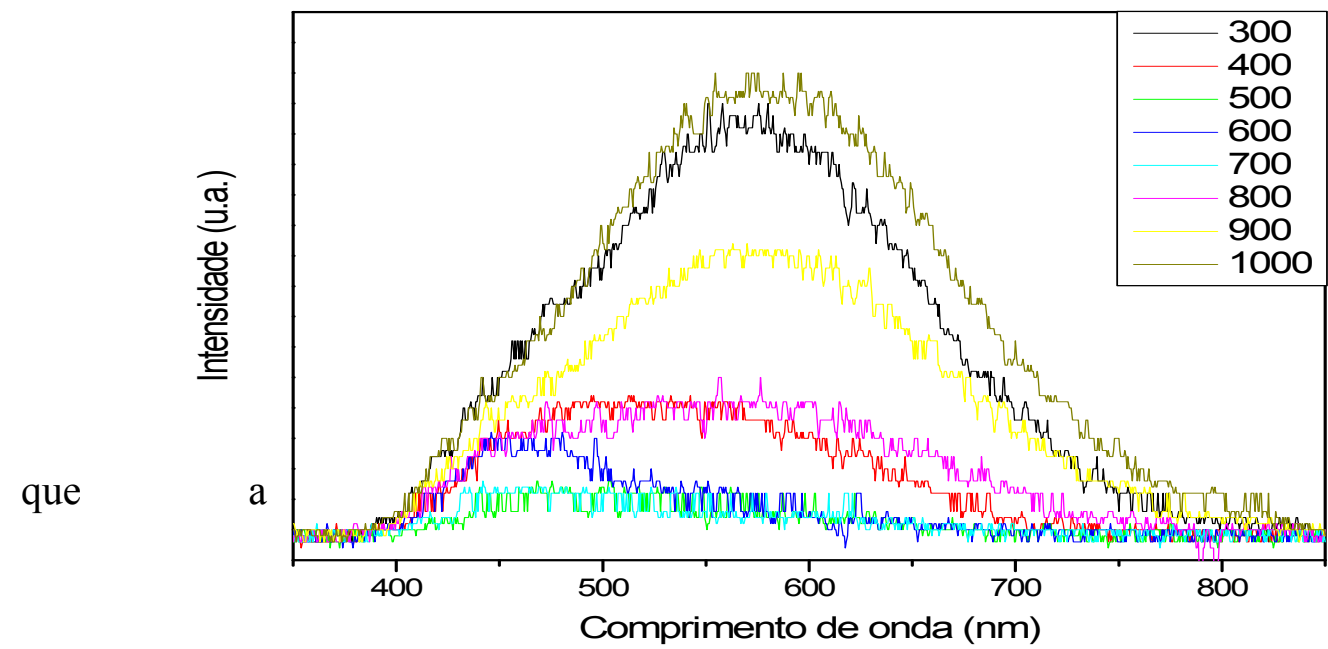

Observou-se atividade 
fotoluminescente foi maior nos extremos das temperaturas, ou seja, nas temperaturas de $300^{\circ} \mathrm{C}$ e $1000^{\circ} \mathrm{C}$, podem-se observar os maiores picos de atividade. Já em temperaturas que entornam os $500^{\circ} \mathrm{C}$ essa atividade foi extremamente baixa e isso está associado à cristalinidade das amostras e ao grau de ordem e desordem intrínseca do material que proporciona atividade fotoluminescente quando estas duas características tornam-se evidentes.

Para a amostra calcinada a $300^{\circ} \mathrm{C}$, tem-se material com pouca cristalinidade e muito desordenado, o qual nesta temperatura já apresenta traços de fase formada pelos picos evidenciados no difratograma de raios- $X$ da amostra, mas ainda apresentando característica pouco cristalina e pela alta presença de material orgânico provindo da síntese.

Já para o material tratado termicamente em $1000^{\circ} \mathrm{C}$, observa-se características de alta cristalinidade, como pode se observar no difratograma de raios $\mathrm{X}$ da amostra, apresentando uma elevada atividade fotoluminescente em relação às demais devido ao seu alto grau de ordenação estrutural. Nas temperaturas em torno dos $500^{\circ} \mathrm{C}$, tem-se o material iniciando sua ordenação e, devido a isso, apresenta ordem e desordem baixas resultando em pouca atividade fotoluminescente.

\subsection{Microscopia Eletrônica de Varredura}

A figura 4 traz imagens obtidas pela Microscopia Eletrônica de Varredura dos pós sintetizados nas temperaturas de 700 e $1000^{\circ} \mathrm{C}$ respectivamente, ambas com ampliação de 2500 vezes.

Figura 4 - Microscopia Eletrônica de Varredura (MEV) das amostras calcinadas a $700^{\circ} \mathrm{C}$ (a) e $1000^{\circ} \mathrm{C}(\mathrm{b})$, ambas com aproximação de 2500 vezes.

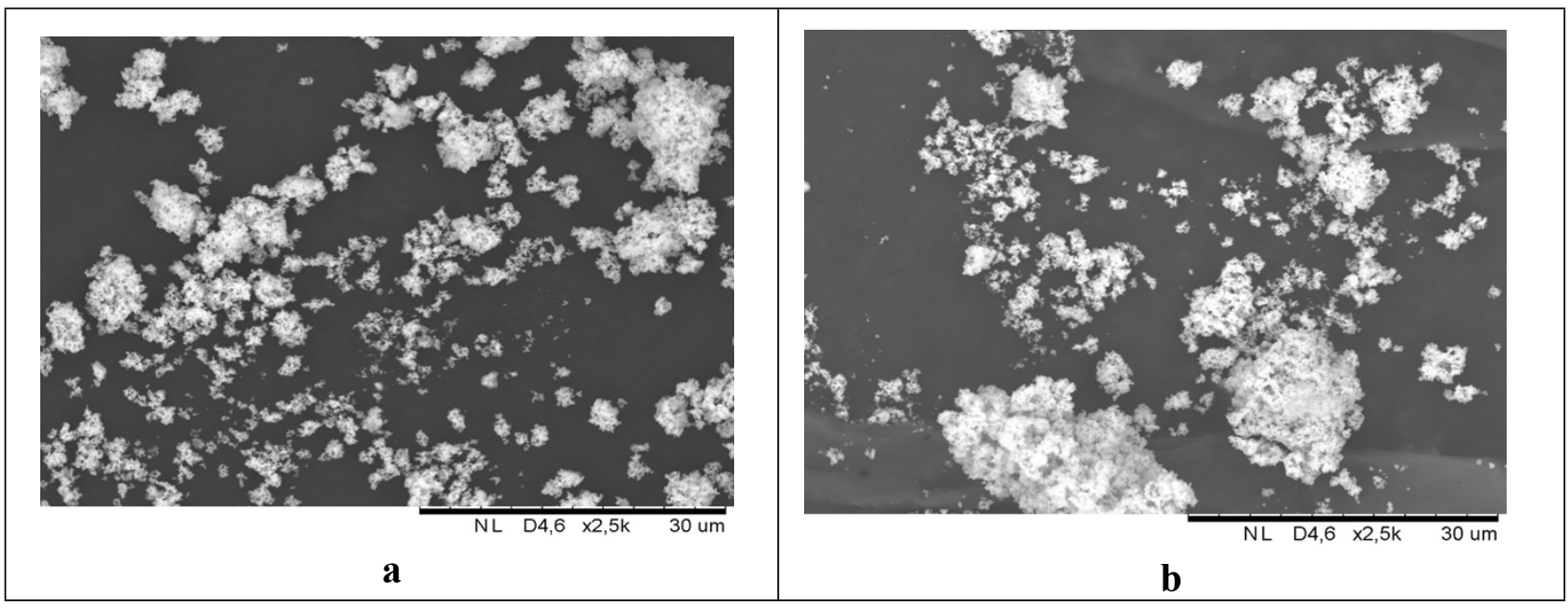

Comparando-se as imagens obtidas através da Microscopia Eletrônica de varredura das calcinações em 700 e $1000^{\circ} \mathrm{C}$, pode-se observar que, em ambas as imagens, as partículas encontram-se aglomeradas e policristalinas. Em relação à influência da temperatura sobre a morfologia do material, pode-se afirmar que o tamanho das partículas aumenta com o aumento da temperatura devido ao efeito de coalescência. 


\section{CONCLUSÃO}

Através da análise térmica, pode-se verificar que a atmosfera oxidativa auxilia na formação do sistema e decomposição da matéria orgânica adjacente em uma menor temperatura. Os resultados de DRX mostraram que o produto final das calcinações é o sistema $\mathrm{MgO}-\mathrm{CeO}_{2}$ e que, mesmo nas temperaturas mais baixas, os picos de difração já evidenciavam a presença deste material em fase com ordem e desordem e que, com o aumento da temperatura, a cristalinidade aumenta juntamente com a organização estrutural. As análises de fotoluminescência mostraram que os pós precursores que apresentaram a maior atividade deste fenômeno foram os calcinados a 300 e $1000^{\circ} \mathrm{C}$ e baixa atividade para os calcinados em temperaturas de 500,600 e $700^{\circ} \mathrm{C}$ devido à cristalinidade e ao grau de ordem e desordem apresentados pelos pós sintetizados. As imagens obtidas pela Microscopia Eletrônica de Varredura mostraram que o material encontra-se policristalino e aglomerado quando calcinado em temperaturas mais baixas e que possuem uma não homogeneidade no tamanho dos grãos quando submetidos a calcinações em temperatura mais elevadas.

\section{REFERÊNCIAS}

[1] HUANG, C.; WANG, S.; CHEN, Y.; LI, B.; LIN, Y., Investigation of the electrical properties of metaleoxideemetal structures formed from RF magnetron sputtering deposited $\mathrm{MgTiO}_{3}$ films, Current Applied Physics, v. 12, p. 935-939, 2012.

[2] KSIAZEK, M., The experimental investigations of propriety and applies in the building special coating - Sulfur polymer composite as the industrial waste material, Composites: Part B, v. 58, p. 378-385, 2014.

[3] HERNANDEZ, M.T.; GONZALEZ M., Synthesis of resins as alpha-alumina precursors by the Pechini method using microwave and infrared heating, Journal of the European Ceramic Society, v.22, p. 2861-2868, 2002.

[4] NOBRE M.A.L.; LANFREDI S., Dielectric properties of $\mathrm{Bi}_{3} \mathrm{Zn}_{2} \mathrm{Sb}_{3} \mathrm{O}_{14}$ ceramics at high temperature, Materials Letters, v. 47, p. 362-366, 2001.

[5] LEITE, E. R.; VARELA, J. A.; LONGOA E. \& C. A. Paskocimasa, Influence of Polymerization on the Synthesis of SrliO: Part II. Particle and Agglomerate Morphologies, Ceramics International, v. 21, p. 153-I58, 1995.

[6] SATO, S., KOIZUMI, K., NOZAKI, F. Ortho-Selective Methylation of Phenol Catalyzed by $\mathrm{CeO}_{2}-\mathrm{MgO}$ Prepared by Citrate Process, Journal of Catalysis, v. 178, p.264-274, 1998.

[7] SINISSE, C.A.L. Obtenção de estruturas celulares de óxido de Cério a partir de Solução colloidal e caracterização de sua microestrutura e atividade catalítica na combustão do metano, Tese de mestrado, UFRGS, 2012.

[8] SHI, Q., LIU, C., CHEN, W. Hydrogen production from steam reforming of ethanol over $\mathrm{Ni} / \mathrm{MgO}-\mathrm{CeO}_{2}$ catalyst at low temperature, Institute of Applied Chemistry, Journal of Rare Earths, v. 27, p.948, 2009.

[9] WANG, R., DONG, Z., LUO, J., CHEN, W., ZHENG, W., GUZONAS, D. Stability of $\mathrm{MgO}-, \mathrm{CeO}_{2}$ - and $\mathrm{SiO} 2$ - doped $\mathrm{Cr}_{2} \mathrm{O}_{3}$ ceramics in high-temperature supercritical water, v. 82, P.339-346, 2014. 